\title{
Horticultural Therapy Program for the Improvement of Attention and Sociality in Children with Intellectual Disabilities
}

\author{
Bo-Young Kim ${ }^{1}$, Sin-Ae Park ${ }^{2}$, Jong-Eun Song ${ }^{1}$, \\ and Ki-Cheol Son ${ }^{1,2,3}$
}

AdDITIONAL INDEX wORDs. Conners' teacher rating scales-revised, social skills rating system, sociohorticulture, human issues in horticulture, people-plant interaction

SumMARY. This study was conducted to determine the effects of a horticultural therapy (HT) program, based on B.F. Skinner's behavior modification theory and special education science curriculum for Korean children with intellectual disabilities for the improvement of attention and sociality. Twenty-four participants (10 males, 14 females, in grades 1 to 3 ) with intellectual disabilities were recruited from a special education class at an elementary school in Seoul, South Korea. Twelve children participated in the HT program after-school for 6 months (Mar. to Aug. 2009 , once per week, $\approx 40$ min per session); the control group consisted of the remaining 12 children. Before and after the HT program, Conners' teacher rating scales-revised and the social skills rating system assessments were conducted by parents/caregivers or teachers for each of the children. Analysis of covariance (ANCOVA) and chi square tests were used to compare differences between the two groups. Difference in attention was not significant between groups. Children in the HT group had statistically significant higher sociality scores than those in the control group $(P<0.001)$. In conclusion, the HT program improved the sociality of children with intellectual disabilities. To maximize the therapeutic effects of the HT program for attention, the program should be revised and supplemented based on the results in this study. A larger sample size and factoring in the level of disability and year in school of the participants would increase the precision in assessing therapeutic effects.

$\mathrm{C}$ hildren with intellectual disabilities are in many ways similar to other children (e.g., weight, height, muscle coordination) but have lower lung capacity and resistance, as well as weaker eyesight, hearing, and motor control (Smith et al., 2005). Their intellectual development is slower resulting in significant disabilities or arrested intellectual capabilities (Smith et al., 2005). In addition, it is difficult for these children to focus on a task and they are easily distracted because of lower visual and perceptive capabilities (Kim and Park, 2007). This lack of attention is accompanied by symptoms of attention deficit hyperactivity disorder (ADHD) (Parker, 1992). The children's cognitive development capabilities are markedly low with weak abilities in terms of social skills (e.g., self-assertion,

${ }^{1}$ Department of Horticultural Therapy, Graduate School of Agriculture and Animal Science, Konkuk University, Seoul 143-701, Korea

${ }^{2}$ Department of Environmental Sciences, Konkuk University, Seoul 143-701, Korea

${ }^{3}$ Corresponding author. E-mail: kcson@konkuk.ac.kr. self-control, cooperation) and they tend to avoid social relationships (Smith et al., 2005). The categories of intellectual disability are based on intelligence quotients (IQs). Those with an IQ $\leq 34$ are classified as grade 1 and require the life-long protection of a caregiver because of their considerable difficulty with everyday life and adaptation in social settings. Those with IQs from 35 to 49, grade 2 disabilities, are able to be trained to succeed at simple everyday activities and can hold uncomplicated jobs that do not require a special technology. Those with IQs from 50 to 70 are classified as grade 3 and can undergo social and occupational rehabilitation via training (Kim, 2009b).

According to the Skinner's behavior modification theory which is composed of stimulus (environment) $\rightarrow$ response (action) $\rightarrow$ reinforcement (result), children are led to reinforce desirable actions through providing compensations for appropriate actions that they took by chance in response to external stimulus (Skinner, 1957). Skinner's theory is widely used by special education teachers for children with disabilities to improve voluntary will (Dollard and Miller, 1950; Sundberg and Michael, 2001). In addition, the children talk less in class and display a decrease in distractive behaviors (Kim, 1993). Several studies have also shown improvement in implementing learned tasks (Kim, 1997; Yoo, 2002).

The efficacy of HT became apparent when horticultural activities were tested on people with mental disabilities and children with intellectual disabilities. A positive impact of HT on children with intellectual disabilities was established with improvements in attention and motivation (Kang, 1998), sociality and social relationships, selfconcept and linguistic communication skills (Cho, 2001; Kim, 2001; Lee, 2004). In addition, their self-confidence and self-efficacy was strengthened (Lee, 2008). Horticultural activities also reduce inappropriate behavior and stress in children with intellectual disabilities (Doxon et al., 1987; Kang, 1998; Sim, 2007) and enhanced their self-concept (Han, 2007). Moreover, outdoor activities like soccer or fishing in green settings or playing in green environments, including grass, trees, or wild places improved attention deficit disorder that reduces children's attention capacity and positively affects to their school life, interpersonal relationships, or personal growth (Sundberg and Michael, 2001; Taylor et al., 2001).

The objective of this study was to test the effect of a HT program that was developed using Skinner's behavior modification theory and the special education science curriculum for Korean children with intellectual disabilities for the improvement of attention and sociality.

\section{Materials and methods}

Subjects. Twenty-four students (10 male and 14 female) with disabilities from school grades 1 to 3 , attending a special education class at an elementary school in K District, Seoul, South Korea, participated in the study. A study description, including consent form, was distributed to parents/caregivers of the students and then the children were decided to participate in the HT program according to their schedules. Twelve children with disabilities participated in the HT program while the remaining 12 were placed in the control group. Before 
implementation of the program, a survey was prepared and distributed to parents/caregivers to record demographic data (e.g., gender, age, disability level, family, use of alternative treatments) for the children.

RESEARCH PERIOD AND ENVIRONMENT. The HT program was administered after-school at a welfare center for the disabled in Seoul. The program was conducted by a horticultural therapist and two assistant therapists in the afternoon for $40 \mathrm{~min}$ per session, once per week between Mar. and Aug. 2009 for a total of 24 sessions. The length of the sessions and duration of the program were based on clinical results indicating that HT programs aimed at mental and psychological rehabilitation are more effective if conducted over an extended period at a lower frequency (i.e., one to two sessions per week over 6 months) (Son et al., 2006). The attendance rate of the participants was $86.5 \%$. A classroom in the welfare center that had an outdoor garden was used for the HT program. The classroom was furnished with movable desks and chairs, was brightly lit, and had good ventilation and little distractive noise. The garden used for outdoor activities was equipped with water lines and was $13.23 \mathrm{~m}^{2}$ in size.

HORTICULTURAL THERAPY PROGRAM. The purpose of the HT program was to improve attention and sociality of children with intellectual disabilities. Skinner's behavior modification theory was applied as the medical treatment intercession model in the program while activities for the program were developed based on the life section in the science curriculum of the seventh special education core program for Korea (Lee et al., 2007). Out of the four sections of the science curriculum, life was chosen because it is aligned with the characteristics of horticulture in which the students take care of living organisms (Son et al., 2006). From the life section, stage 1 (individual life and family life) and stage 2 (school life and social life) were applied to the HT program; stage 3 (economic life and leisure life) was excluded in that because it was inappropriate for children with significant learning abilities (Shin, 2008). In stage 1 , the students are taught to distinguish life from non-life, the appearances of animals and plants, and the exterior appearance and functions of human bodies. In stage 2 , the students are taught characteristics of life and non-life, the structure, function, and circulatory process of human body.

The 24 session HT program was composed of three sessions of gardening activities [cultivating a vegetable garden, tying plants to stakes, cooking pajeon (spring onion pancakes, a Korean traditional food) after the harvest] and 21 sessions of indoor activities (planting seed; making a flower basket, a potpourri, a bouquet, natural soap, a wreath, a fan using pressed flowers, sunflower puzzles, natural dye; and planting herbs and doing aquaculture with foliage plants). Out of the 24 sessions, six sessions were group activities while in the remainder, the students engaged in individual activities within groups.

In each of the 24 sessions, the activity materials were stimulus to motivate for horticultural activities and compliments for the actions to complete the given activity, and outcomes in the sessions were reinforcement (Fig. 1). All procedures in each therapy session also included therapeutic intend to induce the therapeutic effects for the targeted variables such as attention and sociality in this study. For example, to reduce hyperactivity behavior that is a construct of attention, creative destruction activities that a new creation (Son et al., 2006), and a group activity with others to improve cooperation were included in the HT program. Each therapy session started with a discussion of the date and weather, followed by the activity for the day that was introduced to provide motivation and provoke curiosity during the course of the therapy. At is a destructive action for producing

the end of each section, the students were told to write their names on their work, present their work, and clean up around themselves to enhance their self-confidence, coordination, and responsibility.

Diverse materials were used for each session to improve the attention of children with visual attention deficiency caused by a lack of perceptive capability. Visual perception therapy techniques such as finding objects of the same size in a group of differing sizes, grouping according to size, finding the same shape, and grouping by shape were included in the program (Kang and Kim, 2006). The students were cautioned about using dangerous tools and materials (e.g., gardening scissors, glue gun, wires) during the program.

Assessment. To validate the efficacy of HT, before and after the program was completed, the attention and sociality of all the students were evaluated. The evaluation was conducted within one week before and after the program using surveys mailed to the parents/caregivers.

To assess the attention, CTRS-R (short version) was used (Conners, 1989). This rating scale is used to evaluate ADHD by teachers for children and teenagers from ages 3 to 17 years (Conners, 1969; Conners et al., 1998; Goyette et al., 1978). The four-point Likert scale $(0=$ rarely, 1 = at times, 2 = frequently, $3=$ very frequently) is composed of four subcategories including oppositional (e.g., violent outburst), hyperactivity (e.g., following instructions of teachers), inattention (e.g., attention to teacher's direction), and ADHD index (e.g., getting along with others) with 28

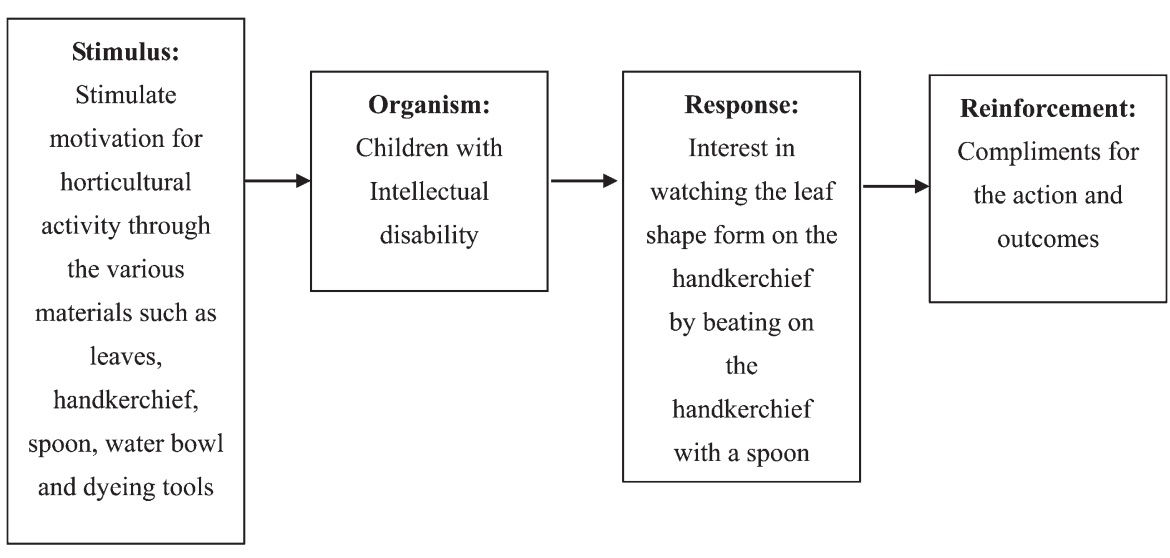

Fig. 1. An example of a horticultural therapy session based on B.F. Skinner's theory of behavior modification: Natural dyeing a handkerchief using leaves. 
questions with total score ranging from 0 to 84 . The lower the point total in each section indicates better attention. In general, 15 points is considered to be the cutoff criteria of ADHD (Oh, 1990; Oh and Lee, 1989; Parker, 1992). The Cronbach's $\alpha$ coefficient of the survey was 0.94 (Conners et al., 1998), whereas the Cronbach's $\alpha$ coefficient in this study was 0.82 .

To assess the sociality of the children, the SSRS (Gresham and Elliott, 1990) was used, which evaluates the social skills of young children and teenagers (3 to 18 years) (Kim, 1996). It is composed of a list of social skills, problem behaviors, and academic competence that are evaluated by parents, teachers, and students, respectively. The social skills scale for teachers is composed of assertion, self-control, cooperation subcategories and for parents is composed of cooperation, assertion, responsibility, and self-control. Each question uses a three-point Likert scale $(0=$ never, $1=$ sometimes, 2 = frequently) for scoring; the point total for each section is an estimate of the student's social skills. The scale for teachers is composed of 30 questions (e.g., yield to others) with social skills ranging from 0 to 60 points. The scale for parents is composed of 38 questions (e.g., help family members voluntarily) with a range of 0 to 76 points. Higher points indicate superior social skills. The Cronbach's $\alpha \mathrm{co}^{-}$ efficients for teachers and parents were 0.9 and 0.95, respectively (Gresham and Elliott, 1990), and in this research they were 0.77 and 0.80 , respectively, confirming their reliability.

Data Analysis. To compare the HT and control groups for attention and sociality, ANCOVA was conducted using SAS PROC GLM (SAS version 9 for Windows; SAS Institute, Cary, NC). At baseline, more students in the control group attended art therapy $(P=0.003)$ so art therapy was a covariant in analysis. Furthermore, the chi square test using SAS PROC FREQ was leveraged to compare demographic data of the HT and control groups using 0.05 as the level of significance.

\section{Results and discussion}

Demographic information. There were no significant differences between the HT and control groups regarding the gender, school year, level of disability, family, and number of siblings of the children (Table 1).

Table 1. Chi square analysis of participant demographics as reported by parents or caregivers to ensure equal distribution between horticultural therapy (HT) $(N=12)$ and control groups $(N=12)$ in the study of the HT program for the improvement of attention and sociality in children with intellectual disabilities.

\begin{tabular}{|c|c|c|c|c|}
\hline Variable & & $\begin{array}{c}\mathrm{HT} \\
{[n(\%)]}\end{array}$ & $\begin{array}{l}\text { Control } \\
{[n(\%)]}\end{array}$ & Significance ${ }^{\mathrm{z}}$ \\
\hline \multirow[t]{2}{*}{ Gender } & Male & $5(41.7)^{\mathrm{y}}$ & $5(41.7)$ & \multirow[t]{2}{*}{ NS } \\
\hline & Female & $7(58.3)$ & $7(58.3)$ & \\
\hline \multirow{3}{*}{$\begin{array}{l}\text { Elementary school } \\
\text { year }^{x}\end{array}$} & Grade 1 & $2(16.7)$ & $1(8.3)$ & \multirow[t]{3}{*}{ NS } \\
\hline & Grade 2 & $2(16.7)$ & $3(25)$ & \\
\hline & Grade 3 & $8(66.7)$ & $8(66.7)$ & \\
\hline \multirow[t]{3}{*}{ Level of disability } & Grade 1 & $1(8.3)$ & $3(25)$ & \multirow[t]{3}{*}{ NS } \\
\hline & Grade 2 & $3(25)$ & $2(16.7)$ & \\
\hline & Grade 3 & $8(66.7)$ & $7(58.3)$ & \\
\hline \multirow[t]{3}{*}{ Type of household } & Parents & $11(91.7)$ & $11(91.7)$ & \multirow[t]{3}{*}{ NS } \\
\hline & Single father & 0 & 0 & \\
\hline & Single mother & $1(8.3)$ & $1(8.3)$ & \\
\hline \multirow{4}{*}{$\begin{array}{l}\text { Number of sibling } \\
\text { (exclude participant) }\end{array}$} & 1 & $8(66.7)$ & $6(50)$ & \multirow[t]{4}{*}{ NS } \\
\hline & 2 & $1(8.3)$ & $1(8.3)$ & \\
\hline & 3 & 0 & $1(8.3)$ & \\
\hline & None & $3(25)$ & $4(33.3)$ & \\
\hline \multirow{6}{*}{$\begin{array}{l}\text { Current alternative } \\
\text { therapy }\end{array}$} & Music & $3(25)$ & $7(58.3)$ & NS \\
\hline & Art & $1(8.3)$ & $8(66.7)$ & * \\
\hline & Physical & $6(50)$ & $7(58.3)$ & NS \\
\hline & Speech & $10(83.3)$ & $11(91.7)$ & NS \\
\hline & Play & $1(8.3)$ & $2(16.7)$ & NS \\
\hline & Others & $4(33.3)$ & $7(58.3)$ & NS \\
\hline
\end{tabular}

${ }^{\mathrm{z}}$ All variables were tested by chi square test at $P=0.05 ; \mathrm{NS},{ }^{*}$ Nonsignificant or significant at $P<0.05$, respectively. y The percentage sum for some variables is over $100 \%$ because those were rounded off numbers to two decimal places, and respondents could mark "all that apply" for the current alternative therapy.

${ }^{\mathrm{x}}$ Grade $\mathrm{l}=7$ years old, grade $2=8$ years old, grade $3=9$ years old

More than half of the children in both groups were grade 3 (9 years old) in elementary school and had a disability level of $3 ; 58.3 \%$ of the students were female and $41.7 \%$ were male in both groups. However, there was a significant difference $(P=0.003)$ in the number of students participating in art therapy, with $66.7 \%$ of the control vs. $8.3 \%$ of the HT group.

EFFECT OF HORTICULTURAL THERAPY ON ATTENTION. To compare the effect of HT program between the HT and control groups on attention, the pretest value and the value of art therapy, which had a significant demographic effect, were used as covariance in the analysis. There was no statistically significant difference found on the overall CTRS-R scores or within individual subcategories when comparing the children who took part in the HT program with children in the control group (Table 2). Based on research by $\mathrm{Oh}$ and Lee (1989), elementary school students with scores higher than 15 were considered ADHD, which indicated that the disability level of children in both the HT and control groups was severe (Table 2 ).

Although there was not significant improvement on attention in this study, expressing and sublimating negative behaviors through creative destructive actions such as cutting, breaking, sticking, and crumbling material for various horticultural activities (e.g., arranging flowers, making bouquets, planting herbs) during each session may have a potential to improve attention and hyperactivity (Son et al., 2006). Trancik and Evans (1995) suggested that day care settings should include green natural spaces for children's attention because the green natural settings may recover mental fatigue of preschool children who may be susceptible to be adapted a new preschool environment. By playing in outdoor green settings, children reduced 
their attention deficit symptoms since contacting with nature may improve attentional functioning of children (Taylor et al., 2001). Often children with intellectual disabilities give up easily when faced with complicated tasks or a difficult teaching method (Kang, 1992), increasing their hyperactivity and reducing their concentration (Lee and Jo, 1991). The current HT program used various objects and different plants, horticultural tools, and landscape photos to increase the curiosity and expectations of the children (Park, 2006). Using uncomplicated activities helps to reduce distractive behaviors.

EFFect of horticultural THERAPY ON SOCIABILITY. With the SSRS for teachers and parents, the initial test value and art therapy value were used as covariance in the analysis. Children who participated in the HT program showed notably higher sociality than the control group (teachers $P=0.0007$, parents $P=0.002$ ) (Tables 3 and 4). This was consistent with prior research that revealed sociality of children with intellectual disabilities improves when they receive HT (Cho, 2001; Hwang, 2006; Kim, 2001; Sim, 2007). In the scale for teachers, all three subcategories [e.g., assertion $(P=0.04)$, self-control $(P=$ $0.0003)$, cooperation $(P=0.0008)]$ displayed statistically significant differences (Table 3). When parents evaluated the students, excluding cooperation $(P=0.06)$, the three subcategories of assertion $(P<0.0001)$, responsibility $(P=0.05)$, and self-control $(P=$ $0.05)$ showed statistically significant differences (Table 4). Although a statistically significant difference was not identified for cooperation in the scales for parents, the children who participated in the HT showed a higher tendency for cooperation.

A distinctive feature differentiating HT from other alternative therapies is that it uses group activities, which provide opportunities for cooperating and interacting with others. The HT program included various common activities for each session (e.g., gardening, arranging flowers, delivering ingredients to someone else, cleaning up) so that children could carry out their tasks in a group, follow rules and work with other children, whereby increasing interactions and enhancing the opportunity to learn cooperation, self-control, assertion, and

Table 2. Analysis of adjusted Conners' teacher rating scales-revised (short version $)^{\mathrm{z}}$ means for students with intellectual disabilities, with $(N=12)$ and without $(N=12)$ horticultural therapy $(\mathrm{HT})$, assessed at the end of the program.

\begin{tabular}{|c|c|c|c|}
\hline $\begin{array}{l}\text { Intellectual } \\
\text { disability }\end{array}$ & $\begin{array}{c}\text { HT [0-3 scale } \\
(\text { mean } \pm \text { SE })]\end{array}$ & $\begin{array}{c}\text { Control }[0-3 \\
\text { scale }(\text { mean } \pm \mathrm{SE})]\end{array}$ & Significance ${ }^{\mathrm{y}}$ \\
\hline \multicolumn{4}{|l|}{ Subcategory } \\
\hline Oppositional & $6.9 \pm 1.7^{x}$ & $7.0 \pm 1.7$ & NS \\
\hline Hyperactivity & $5.9 \pm 1.4$ & $8.1 \pm 1.4$ & NS \\
\hline Inattention & $9.3 \pm 1.5$ & $8.3 \pm 1.5$ & NS \\
\hline $\begin{array}{l}\text { Attention deficit hyperactivity } \\
\text { disorder (ADHD) index }\end{array}$ & $9.6 \pm 2.0$ & $10.5 \pm 2.0$ & NS \\
\hline Total & $31.1 \pm 6.3$ & $34.4 \pm 6.3$ & NS \\
\hline
\end{tabular}

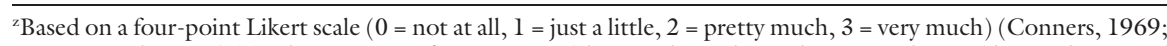
Conners et al., 1998). Total score ranges from 0 to 84 . A lower value indicates better condition. Above 15 points of total score is classified as ADHD (Oh, 1990; Oh and Lee, 1989).

$\mathrm{y}_{\mathrm{NS}}=$ Nonsignificant by analysis of covariance (ANCOVA) at $P<0.05$.

${ }^{\mathrm{x}}$ Adjusted for pretest and art therapy in demographic categories values as covariate by ANCOVA at $P=0.05$.

Table 3. Analysis of adjusted social skill means from the social skills rating system $^{z}$ for students with intellectual disabilities, with $(N=12)$ and without $(N=12)$ horticultural therapy (HT), assessed by teachers at the end of the program.

\begin{tabular}{lccc}
\hline Social skills & $\begin{array}{c}\text { HT }[1-3 \text { scale } \\
(\text { mean } \pm \text { SE) }]\end{array}$ & $\begin{array}{c}\text { Control }[1-3 \\
\text { scale }(\text { mean } \pm \mathrm{SE})]\end{array}$ & \begin{tabular}{c} 
Significance $^{\mathrm{y}}$ \\
\hline Subcategory
\end{tabular} \\
Self-assertion & $11.3 \pm 1.2^{\mathrm{x}}$ & $7.1 \pm 1.2$ & * \\
Self-control & $11.9 \pm 1.1$ & $4.3 \pm 1.1$ & $* *$ \\
Cooperative & $12.7 \pm 0.9$ & $7.3 \pm 0.9$ & $* *$ \\
Total & $36.0 \pm 2.8$ & $18.5 \pm 2.8$ & $* *$ \\
\hline
\end{tabular}

${ }^{z}$ Based on three-point Likert scale ( 1 = not at all, $2=$ sometimes, $3=$ often $)$ (Gresham and Elliott, 1990). Total score ranges from 0 to 60 . A high value indicates higher sociality.

y* ${ }^{* *}$ Significant by analysis of covariance (ANCOVA) at $P<0.05$ or 0.001 , respectively.

${ }^{\mathrm{x}}$ Adjusted for pretest and art therapy in demographic categories values as covariate by ANCOVA at $P=0.05$.

Table 4. Analysis of adjusted social skill means from the social skills rating system $^{z}$ for students with intellectual disabilities, with $(N=12)$ and without $(N=12)$ horticultural therapy (HT), assessed by parents at the end of the program.

\begin{tabular}{|c|c|c|c|}
\hline Social skills & $\begin{array}{c}\mathrm{HT}[1-3 \text { scale } \\
(\text { mean } \pm \mathrm{SE})]\end{array}$ & $\begin{array}{c}\text { Control }[1-3 \\
\text { scale }(\text { mean } \pm \mathrm{SE})]\end{array}$ & Significance ${ }^{\mathrm{y}}$ \\
\hline \multicolumn{4}{|l|}{ Subcategory } \\
\hline Cooperation & $10.8 \pm 1.2^{\mathrm{x}}$ & $7.2 \pm 1.2$ & NS \\
\hline Self-assertion & $9.7 \pm 0.6$ & $3.9 \pm 0.6$ & * \\
\hline Responsibility & $6.4 \pm 0.7$ & $4.0 \pm 0.7$ & ** \\
\hline Self-control & $7.8 \pm 0.9$ & $4.9 \pm 0.9$ & $* *$ \\
\hline Total & $35.0 \pm 2.8$ & $19.6 \pm 2.8$ & $* * *$ \\
\hline
\end{tabular}

${ }^{2}$ Based on three-point Likert scale ( $1=$ not at all, 2 = sometimes, $3=$ often) (Gresham and Elliott, 1990). Total score ranges from 0 to 76 . A high value indicates higher sociality.

${ }^{{ }^{\mathrm{NS}}}=$ Nonsignificant by analysis of covariance (ANCOVA) at $P<0.05 ;{ }^{*},{ }^{*},{ }^{* * *}$ significant by ANCOVA at $P<$ $0.05,0.01$, or 0.001 , respectively.

${ }^{x}$ Adjusted for pretest and art therapy in demographic categories values as covariate by ANCOVA at $P=0.05$.

responsibility. The students were able to select their own materials (e.g., pots, plants) for activities such as flowers for arranging, although they followed the instructions for trimming and cutting the flowers, increasing sense of achievement and self-confidence (Kim, 2009a) which are thought to improve their assertiveness.

In conclusion, the use of a HT program, based on Skinner's behavior modification theory and the life section in the science curriculum of the seventh special education program, resulted in a significant improvement in the sociality of children with intellectual disabilities. In order for the HT program to have a major impact, future research should take into consideration the levels of disability, year in school, number of participants, and other factors. 


\section{Literature cited}

Cho, H.G. 2001. Effect of horticultural therapy on the adaptive behavior of student with mental retardation. Donga Univ., Busan, Korea, MS Diss.

Conners, C.K. 1969. A teacher rating scale for use in drug studies with children. Amer. J. Psychiatry 126:884-888.

Conners, C.K. 1989. Conners' rating scales manual. Multi-Health Systems, North Tonawanda, NY.

Conners, C.K., G. Sitarenios, J.D. Parker, and J.N. Epstein. 1998. Revision and restandardization of the Conners teacher rating scale (CTRS-R): Factor structure, reliability, and criterion validity. J. Abnorm. Child Psychol. 26:279-291.

Dollard, J. and N.E. Miller. 1950. Personality and psychotherapy. McGraw-Hill, NY.

Doxon, L.E., R.H. Mattson, and A.P. Jurich. 1987. Human stress reduction through horticultural vocational training. HortScience 22:655-656.

Goyette, C.H., C.K. Conners, and R.F. Ulrich. 1978. Normative data on revised Conners parent and teacher rating scales. J. Abnorm. Child Psychol. 6:221-236.

Gresham, F.M. and S.N. Elliott. 1990. Social skills rating system manual. American Guidance Service, Circle Pines, MN.

Han, C.S. 2007. The effect of horticultural therapy on the self-concept of students with intellectual disability. Daegu Univ., Daegu, Korea, MS Diss.

Hwang, D.H. 2006. A study on the effects of horticultural therapy on the sociality of mentally retarded students. Daegu Univ., Daegu, Korea, MS Diss.

Kang, H.J. and Y.I. Kim. 2006. The effects of a visual perception training program on improving the attention behavior of students with mental retardation. J. Special Children Educ. 8:213-232.

Kang, H.K. 1992. The study on drawing activity for students with mental retardation. Ewha Womens Univ., Seoul, Korea, MS Diss.

Kang, J.S. 1998. The effect of horticultural activities on the adaptive behavior children with mental retardation. Kongju National Univ., Kongju, Korea, MS Diss.
Kim, B.Y. and S.H. Park. 2007. Effects of instructional adaptations on the problem behaviors and task engagement behaviors of students with disabilities in elementary inclusive classrooms. Korean J. Special Educ. 42:19-49.

Kim, E.Y. 2009a. Effect of horticultural therapy based upon theory of emotional intelligence on the improvement of emotional quotient and sociality of children in the dual-income family. Konkuk Univ., Seoul, Korea, MS Diss.

Kim, H.J. 1996. The validity of social skill rating system. J. Spec. Educ. 17:121-155.

Kim, J.H. 2001. Effectiveness of group horticultural therapy with mental retarded. Hanrim Univ., Chuncheon, Korea, MS Diss.

Kim, J.S. 1993. A study on the effect of token reinforcement method on learning disorder behavior change of elementary school. Korea Natl. Univ. Educ., Chungbuk, Korea, MS Diss.

Kim, S.Y. 2009b. Effect of group art therapy on the change of sociality for intellectual disability children. Hansung Univ., Seoul, Korea, MS Diss.

Kim, T.S. 1997. The effect of token reinforcement technique based on the behavior modification of learning disabilities. Kyungnam Univ., Changwon, Korea, MS Diss.

Lee, J.H. 2004. Effects of horticultural therapy on the adaptive skills of students with intellectual disability. Daegu Univ., Daegu, Korea, MS Diss.

Lee, K.S. 2008. Case study on behavior changes of mentally retarded children in elementary school with gardening activity program applied. Yeungnam Univ., Gyeongsan, Korea, MS Diss.

Lee, S.C. and I.S. Jo. 1991. Selective attention of the educable mentally retarded according to incidental task and transfer operations. J. Speech Hear. Disord. 1:87-122.

Lee, S.P., K.C. Kim, Y.Y. Kim, H.S. Kim, K.D. Moon, J.H. Oh, J.K. Jung, J.H. Jung, C.S. Choi, and M.K. Hwang. 2007. Selection centered curriculum for high school students (job subject). I May 2012. <http://www.kice.re.kr/ko/board/view. do?article_id=60506\&menu_id=10134>.
Oh, K.J. 1990. Assessment of children with attention deficit hyperactivity disorder. J. Korean Acad. Child Adolesc Psychiatry 1:65-76.

Oh, K.J. and H. Lee. 1989. Assessment of ADHD with abbreviated Corners rating scale. Korean J. Clinical Psychol. 8:135142.

Park, J.Y. 2006. Horticultural therapeutic model presentation to the mentally retarded. Dankook Univ., Cheonan, Korea, MS Diss.

Parker, H.C. 1992. The ADD hyperactivity handbook for schools: Effective strategies for identifying and teaching students with attention deficit disorders in elementary and secondary schools. Impact, Plantation, FL.

Shin, I.G. 2008. Leisure activities during the summer break of students with mental retardation from the perspectives of their mothers. Chosun Univ., Kawangju, Korea, MS Diss.

Sim, E.M. 2007. The effect of horticultural therapy on the adaptive behavior of mentally retarded children. Univ. of Seoul, Seoul, Korea, MS Diss.

Skinner, B.F. 1957. Verbal behavior. Prentice Hall, Englewood Cliffs, NJ.

Smith, M.B., J.R. Patton, and S.H. Kim. 2005. Mental retardation: An introduction to intellectual disabilities. 7th ed. Prentice Hall, Englewood Cliffs, NJ.

Son, K.C., M.K. Cho, J.E. Song, S.Y. Kim, and S.S. Lee. 2006. Practice of professional horticultural therapy. Coobook, Seoul, Korea.

Sundberg, M.L. and J. Michael. 2001. The benefits of Skinner's analysis of verbal behavior for children with autism. Behav. Modif. 25:698-724.

Taylor, A.F., F.E. Kuo, and W.C. Sullivan. 2001. Coping with ADD. The surprising connection to green play settings. Environ. Behav. 33:54-77.

Trancik, A.M. and G.W. Evans. 1995. Spaces fit for children: Competency in design of daycare center environments. Children's Environ. 12:311-319.

Yoo, S. 2002. The influence of the token economy on the maladjusted behavior of the underachievers. Woosuk Univ., Jeonbuk, Korea, PhD Diss. 